
\title{
3 Research Square \\ The Effects of Low-dose Empagliflozin on Cardiac Function in a Rat Model of Streptozotocin-induced Diabetes
}

\section{Zeynep Eilf Yesilyurt}

Ankara University Faculty of Pharmacy: Ankara Universitesi Eczacilik Fakultesi Irem Karaomerlioglu

Ankara University Faculty of Pharmacy: Ankara Universitesi Eczacilik Fakultesi

Betül Rabia Erdogan

Ankara University Faculty of Pharmacy: Ankara Universitesi Eczacilik Fakultesi

Gaye Ozturk

Ankara University Faculty of Pharmacy: Ankara Universitesi Eczacilik Fakultesi

Martin C Michel ( $\triangle$ marmiche@uni-mainz.de)

Johannes Gutenberg-Universität Mainz https://orcid.org/0000-0003-4161-8467

Ebru Arioglu-Inan

Ankara University Faculty of Pharmacy: Ankara Universitesi Eczacilik Fakultesi

\section{Research Article}

Keywords: $\beta$-adrenoceptor, diabetes, empagliflozin, heart, pressure-volume analysis

Posted Date: May 22nd, 2021

DOl: https://doi.org/10.21203/rs.3.rs-526255/v1

License: (9) (i) This work is licensed under a Creative Commons Attribution 4.0 International License. Read Full License 


\section{Abstract}

Purpose: Diabetes mellitus is a metabolic disorder leading to cardiovascular complications. Both in vivo cardiac function and $\beta$-adrenoceptor ( $\beta$-AR) mediated responsiveness have been demonstrated to be blunted in the diabetic heart. Sodium glucose co-transporter-2 (SGLT2) inhibitors, such as empagliflozin (EMPA) have shown cardioprotective effects in patients and in some animal models. In this study, we aimed to investigate the effects of low-dose EMPA ( $10 \mathrm{mg} / \mathrm{kg} /$ day) on in vivo cardiac function and $\beta$-ARmediated contractile response in streptozotocin (STZ)-induced diabetic rats.

Methods: 11-12 week old male Sprague Dawley rats were divided into 4 groups; control, EMPA-treated control, diabetic, EMPA-treated diabetic. Diabetes was induced by STZ injection ( $40 \mathrm{mg} / \mathrm{kg}$, i.p.). After 1316 weeks, some of the diabetic and control rats were treated with a low dose of EMPA $(10 \mathrm{mg} / \mathrm{kg} / \mathrm{day}$, oral gavage, once a day) or vehicle for another 8 weeks. At study end, in vivo cardiac function was evaluated by pressure-volume loop analysis. $\beta$-AR mediated contractile response was determined using isoprenaline in papillary muscle preparations.

Results: EMPA did not change cardiac function in control rats. Diabetic rats had a reduced heart rate, cardiac output, stroke work, $+\mathrm{dp} / \mathrm{dt}$ and $-\mathrm{dp} / \mathrm{dt}$ and increased isovolumic relaxation, whereas in vitro responses were reduced to a minor extent. Treatment with EMPA showed a trend for improvement of some but not all parameters.

Conclusion: Our results indicate that low dose EMPA treatment had limited effects on cardiac impairment although it reduced blood glucose. Future studies with a higher dose and greater sample sizes could help to clarify the possible benefits of EMPA on the diabetic heart.

\section{Introduction}

Diabetes remains an important health problem despite the steps taken to better understand its pathophysiology and new treatment approaches (Pennig et al., 2019). According to a survey of the International Diabetes Federation, it is estimated that diabetes affected 451 million people worldwide in 2017 and will affect 693 million by 2045 (Cho et al., 2018). Cardiovascular complications are one of the most important causes of morbidity and mortality in patients with type 1 and type 2 diabetes (T1DM and T2DM, respectively) (Lee et al., 2019b).

A good glycemic control is important to prevent microvascular diabetic complications such as nephropathy, retinopathy and neuropathy. The ACCORD (Gerstein et al., 2008), ADVANCE (Group et al., 2008) and VADT (Duckworth et al., 2009) trials have shown that major cardiovascular events, considered to represent macrovascular complications were inadequately addressed by treatment approaches despite a tight glycemic control. Thus, choosing a drug with beneficial effects on cardiovascular system may help to reduce morbidity and mortality in diabetes. 
Inhibitors of sodium-glucose cotransporter 2 (SGLT2) are antidiabetic drugs that inhibit glucose reabsorption in the renal tubules to stimulate glucose excretion (Michel et al., 2015). Although prescribed mainly for T2DM, SGLT2 inhibitors including empagliflozin (EMPA) are also of interest for T1DM treatment. EMPA reduced body weight and glycosylated hemoglobin ( $\mathrm{HbA1c}$ ) when combined with insulin in a pilot study in patients with new-onset T1DM (Wentworth et al., 2020). Furthermore, the EASE-3 trials evaluating the safety of EMPA as adjunct therapy to insulin in T1DM highlight that the use of a lower dose of EMPA may help to improve $\mathrm{HbA} 1 \mathrm{c}$ and body weight without increasing the risk of ketoacidosis and hypoglycemia (Rosenstock et al., 2018). Similarly, a placebo-controlled study found that sotagliflozin when administered in combination with insulin therapy improved glycemic control in T1DM patients; however, an increased rate of diabetic ketoacidosis has been reported in this group compared to placebo (Garg et al., 2017).

Recent clinical trials such as EMPA-REG OUTCOME (Zinman et al., 2015), CANVAS (Neal et al., 2017) and DECLARE-TIMI (Wiviott et al., 2019) have revealed that patients treated with SGLT2 inhibitors had a lower risk of major cardiovascular events compared with placebo. In the DAPA-HF trial, dapagliflozin reduced worsening of heart failure and cardiovascular mortality compared to placebo in patients with reduced ejection fraction (McMurray et al., 2019). The CVD-REAL clinical trial has reported that SGLT2 inhibitors markedly attenuated hospitalization due to heart failure or all-cause mortality in T2DM patients (Kosiborod et al., 2017). The results of the VERTIS CV trial reveal that ertugliflozin reduces the risk of first and total hospitalization for heart failure in patients with T2DM. These findings support the use of SGLT2 inhibitors to prevent outcomes associated with heart failure (Cosentino et al., 2020).

The cardiac complications of diabetes can be mimicked in animal models. For instance, leptin-deficient homozygous ob/ob mice, an obese T2DM model, exhibited diastolic left ventricular dysfunction, which was improved by a treatment with EMPA (Hammoudi et al., 2017). This was accompanied by beneficial changes of cardiac $\mathrm{Ca}^{++}$regulation and growth signaling pathways. It was suggested that improved $\mathrm{Ca}^{++}$ cycling due to increased SERCA2a/phospholamban (PLN) ratio and enhanced SERCA2a activity may have contributed to enhanced diastolic relaxation (Hammoudi et al., 2017). Female $\mathrm{db} / \mathrm{db}$ mice also exhibited impaired diastolic function, and this was also improved by treatment with EMPA (Habibi et al., 2017). The authors attributed the improved diastolic function to both reduction in blood glucose levels and alterations in cardiac structure. EMPA treatment was also effective in nondiabetic rats with left ventricular dysfunction induced by permanent ligation of left anterior descending coronary artery. In this study, cardiac function, cardiomyocyte hypertrophy and cardiac fibrosis were improved with EMPA treatment (Yurista et al., 2019). Similarly, EMPA attenuated cardiac fibrosis in high fat fed spontaneous hypertensive rat model (Lee et al., 2019a). In addition to this, cardioprotective effects of other SGLT2 inhibitors have been demonstrated. For instance, a reduction in infarction size was found in langendorff perfused hearts of both Zucker Diabetic Fatty (ZDF) and non-diabetic Zucker Lean (ZL) rats fed with canagliflozin (Lim et al., 2019). In another study, dapagliflozin treatment attenuated fibrosis and inflammation and improved the reduced fractional shortening in diabetic $(\mathrm{db} / \mathrm{db})$ mice with angiotensin II 
-induced cardiomyopathy (Arow et al., 2020). These findings imply a cardiac benefit of SGLT2 inhibitors that is at least partly independent of their glucose lowering effect.

An important characteristic of the diabetic heart is a decreased responsiveness to $\beta$-adrenoceptor ( $\beta$-AR) stimulation; e.g. reduced chronotropic responses to $\beta$-AR agonists in animal models with diabetes due to administration of streptozotocin (STZ) (Dincer et al., 1998) or upon induction of obesity (Jiang et al., 2015). Although there are some studies on the cardiac effects of EMPA in experimental diabetes models (Habibi et al., 2017, Hammoudi et al., 2017, Zhou and Wu, 2017), the efficacy of the drug has not been studied in terms of $\beta$-AR mediated responses. Thus, by evaluating in vivo cardiac function and $\beta$-AR responsiveness, we aimed to test whether low dose EMPA has beneficial effects on STZ-diabetic rat heart.

\section{Materials And Methods}

\section{Animals}

Male, Sprague Dawley rats (11-12 weeks old) were obtained from Bilkent University, Department of Molecular Biology and Genetics Animal Unit (Ankara, Turkey) and housed under 12-h light/dark cycle in the Ankara University Faculty of Pharmacy Animal Care Unit. Rats had free access to standard rat chow (Purina Rat Chow; Optima AS, Bolu, Turkey) and tap water. All experimental procedures of the present study were in line with $\mathrm{NIH}$ guidelines for the care and use of experimental animals and had been approved by the Animal Welfare Commitee of Ankara University (2019-4-41).

\section{Induction of Diabetes}

After one week of acclimatization, rats were randomly divided into control and diabetic groups. We set the samples sizes as 14 rats for the control group and 20 rats for the diabetic groups to account for possible attrition in the diabetic groups because of a greater mortality risk. Diabetes was induced by an intraperitonal injection of STZ (40 mg/kg dissolved in citrate buffer at $\mathrm{pH} 4.5)$. Control rats were injected with citrate buffer ( $\mathrm{pH}$ 4.5). Three days after STZ injection, blood glucose was measured and rats with blood glucose higher than $300 \mathrm{mg} / \mathrm{dl}$ were considered as diabetic. If blood glucose levels lower than 300 $\mathrm{mg} / \mathrm{dl}$, a second or third STZ injection was administered.

\section{Treatment with EMPA}

After 13-16 weeks of diabetes, control and diabetic rats were randomly divided into 2 groups each; control, EMPA treated control, diabetic and EMPA treated diabetic. One rat in the diabetic group was euthanized due to poor health condition in this period. Thus, the sample size was set as 7 in each control group, 8 in diabetic and 11 in EMPA treated diabetic group. The sample size was higher in the treated diabetic group regarding the possible mortality risk (e.g., due to hypoglycemia). The treatment was started at 13-16 weeks after STZ injection. For this purpose, EMPA (Jardiance $\left.{ }^{\circledR}\right)$ tablets were crushed and suspended in distilled water. Each tablet includes lactose monohydrate, microcrystalline cellulose, 
hydroxypropyl cellulose, croscarmellose sodium, colloidal anhydrous silica, magnesium stearate. The film coating of the tablets also contains the following; hypromellose, titanium dioxide, talc, macrogol, and yellow ferric oxide. The crushed material was dissolved in $5 \mathrm{ml}$ of distilled water. Treated control and diabetic rats received $10 \mathrm{mg} / \mathrm{kg}$ EMPA (calculated for active pharmaceutical ingredient) by oral gavage, once daily for 8 weeks. The dose was selected based on previous studies, where the lower of two doses under investigation was 10 mg/kg/day (Oelze et al., 2014, Steven et al., 2017, Zhou and Wu, 2017). Control and diabetic rats received distilled water by oral gavage. In the treatment period, one rat from the EMPA treated control group was killed during treatment with gavage. One rat in the diabetic group returned to normoglycemic level and was excluded from the study. Two rats in the EMPA treated diabetic group were euthanized due to a poor health profile. At the end of the treatment period, rats were sacrificed and in vivo and in vitro experiments were performed (control $n=7$, EMPA treated control $n=6$, diabetic $n=7$ and EMPA treated diabetic $n=9$ ).

\section{In vivo measurement of basal hemodynamic parameters}

Pressure-volume (PV loop) analysis was performed as previously reported (Arioglu-Inan et al., 2013). Rats were anesthetized by $2 \%$ isoflurane inhalation and body temperature was monitored to be $37^{\circ} \mathrm{C}$ with a rectal probe during the operation. After making an incision, a PV catheter (Transonic, London, Ontario, Canada) was inserted into right carotid artery. After 3-minute of blood pressure recording, the catheter was advanced into the left ventricle. Following a 10-minute stabilization period, PV loops were recorded. Then, preload-independent cardiac parameters were measured by 5 -second vena cava occlusions. At the end of the experiments, the following basal hemodynamic parameters were calculated; end diastolic pressure (EDP), end systolic pressure (ESP), heart rate (HR), end diastolic volume (EDV), end systolic volume (ESV), cardiac output (CO), ejection fraction (EF), stroke volume (SV), stroke work (SW), rate of contraction $(+d p / d t)$, rate of relaxation (-dp/dt), isovolumic relaxation constant (Tau logistic) and preload independent parameters; preload recruitable stroke work (PRSW), end-systolic pressure-volume relationship (ESPVR), end-diastolic pressure-volume relationship (EDPVR). ESV, EDV, SV and CO were normalized to body weight to eliminate the differences of body weight between animals (ESV index, EDV index, SV index, Cardiac index) (Kim et al., 2010).

\section{In vitro papillary muscle experiments}

The experiments were performed as previously described (Arioglu-Inan et al., 2013). Briefly, rats were anesthetized under $2 \%$ isoflurane inhalation. After PV loop analysis, hearts were rapidly isolated. The extracted hearts were transferred to an oxygenated experimental plate containing heparin and Krebs solution (120 mM NaCl; $4,8 \mathrm{mM} \mathrm{KCl} ; 1.25 \mathrm{mM} \mathrm{CaCl}_{2} .2 \mathrm{H}_{2} \mathrm{O} ; 1.25 \mathrm{mM} \mathrm{MgSO}_{4} .7 \mathrm{H}_{2} \mathrm{O} ; 1.2 \mathrm{mM} \mathrm{KH}_{2} \mathrm{PO}_{4} ; 25$ $\mathrm{mM} \mathrm{NaHCO}_{3}$ and $10 \mathrm{mM}$ glucose at $\mathrm{pH}$ 7.4). Papillary muscles were dissected from the left ventricle and mounted in horizontal organ baths (Harvard Apparatus $\mathrm{GmbH}$, March-Hugstetten, Germany). Electrical field stimulation $(0.6 \mathrm{~Hz}, 2 \mathrm{~ms}$, twice the diastolic threshold) was applied to the muscle (Gauthier et al., 1996) and the organ bath was perfused with Krebs solution $\left(95 \% \mathrm{O}_{2} ; 5 \% \mathrm{CO}_{2} ; 30^{\circ} \mathrm{C}\right)$ at a rate of $5 \mathrm{ml} / \mathrm{min}$. Tension was recorded using a force transducer (HSE F30; Type 372, Harvard Apparatus GmbH). 
Following a 60-minute stabilization period, the maximal tension $\left(L_{\max }\right)$ was found by stretching the papillary muscles with $10 \mu \mathrm{m}$ increments and the experiments were then performed at $90 \%$ of maximal tension. After equilibration, cumulative concentration-response curves of isoprenaline $(0.1 \mathrm{nM}-10 \mu \mathrm{M})$ were obtained.

\section{Chemicals}

EMPA tablets (Jardiance ${ }^{\circledR}, 25 \mathrm{mg}$, Boehringer Ingelheim) were purchased from a pharmacy. The ingredients of Krebs solution, STZ and isoprenaline were obtained from Sigma Aldrich (Darmstadt, Germany). Isoflurane was received from Adeka (Samsun, Turkey). A Bayer glucometer and glucose test strips (Contour Plus, Switzerland) were used to measure blood glucose.

\section{Data analysis}

The efficacy of isoprenaline in the papillary muscle experiments was determined by fitting a 3-parameter model (top, bottom, log $\mathrm{EC}_{50}$ ) of concentration-response curve to the experimental data from each experiment to derive an estimated maximum effect $\left(E_{\max }\right)$. Data are expressed as mean $\pm S D$ and shown as bar graphs overlaid with scatter plots for increased transparency (Michel et al., 2020). To avoid misleading y-axis scaling, all y-axes start at 0 (Erdogan et al., 2020). All statistical analyses were performed with Prism (version 9, GraphPad, La Jolla, CA, USA). As the study was of exploratory nature, the obtained data were not interpreted as hypothesis-testing but only as descriptive. When comparing the healthy control and STZ diabetic groups, we aimed to observe whether cardiomyopathy was developed with $40 \mathrm{mg} / \mathrm{kg} \mathrm{STZ} \mathrm{injection.} \mathrm{Additionally,} \mathrm{the} \mathrm{comparisons} \mathrm{STZ} \mathrm{diabetic} \mathrm{group} \mathrm{versus} \mathrm{EMPA} \mathrm{treated} \mathrm{STZ}$ diabetics were done to explore if $10 \mathrm{mg} / \mathrm{kg}$ of EMPA corrected impaired parameters.

\section{Results}

\section{General characteristics of animals}

STZ injection markedly increased blood glucose, which was substantially attenuated but not fully abolished by EMPA (Fig. 1a), thereby validating the induction of diabetes by STZ and the antidiabetic efficacy of low-dose EMPA in this model. While the control and EMPA treated control groups had similar blood glucose and body weight profiles, diabetic rats had a reduced body weight that was not affected by EMPA (Fig. 1b). Heart weight was similar across all groups leading to a slightly increased heart/body weight ratio in diabetic and EMPA treated diabetic rats (Fig. 1c, d).

\section{In vivo basal hemodynamic parameters}

Systolic (SBP), diastolic blood pressure (DBP) and MAP were measured when the PV loop catheter was inserted in the carotid artery. The values were slightly reduced in the diabetic groups, but no improvement was observed in EMPA treated diabetic group (Table 1). 
Cardiac function parameters were assessed by using the PV loop catheter and most of these parameters are summarized in Table 1. The parameters closely related to systolic and diastolic function are shown in Fig. 2 and 3. Our results indicate that some of the hemodynamic parameters such as HR, $\mathrm{CO}$ and SW were impaired in the diabetic group; however, EMPA treatment did not improve these parameters in diabetics. Other parameters were found similar in all four groups (Table 1).

The systolic function parameters ESP, $+\mathrm{dp} / \mathrm{dt}$ and EF decreased in the diabetic group. These parameters

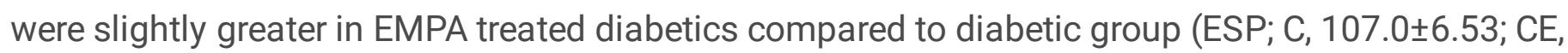
105.10 $\pm 5.84 ; \mathrm{D}, 92.15 \pm 9.34 ; \mathrm{DE}, 96.74 \pm 16.52 ;+\mathrm{dp} / \mathrm{dt}$; C, 6790 $\pm 654.8 ; \mathrm{CE}, 6437 \pm 434.4 ; \mathrm{D}, 4879 \pm 663.5 ; \mathrm{DE}$,

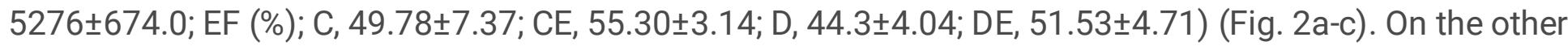
hand, EMPA did not affect systolic function in control animals.

Similarly, diastolic function was impaired in the diabetic group. EMPA shows a slight improvement, however, was unable to normalize the relaxation rate (-dp/dt; C, $-5972 \pm 833.2$; CE, $-5413 \pm 414.4$; D, $-4111 \pm 607.1 ; \mathrm{DE},-4532 \pm 999.5$ ) or the time constant of isovolumic relaxation (Tau) in diabetics (Tau logistic; C, 18.49 $\pm 1.22 ; C E, 19.47 \pm 1.42 ;$ D, 22.79 $\pm 3.01 ; D E, 22.21 \pm 0.97$ ) (Fig. 3a-C).

Preload independent parameters (preload recruitable stroke work, end-systolic pressure volume relationship, end-diastolic pressure volume relationship) were measured by vena cava inferior occlusions for 5 -second. The values are shown in Table 2. The expected deterioration was not observed in the diabetic group, so, it seems unlikely to comment on the effect of EMPA in diabetic animals, however, EMPA had no major effect in the control group.

\section{Contractile responses to the $\beta$-adrenergic agonist isoprenaline on papillary muscle}

In the papillary muscle isolated from the left ventricle of the heart, the $\beta$-adrenergic responses were evaluated with isoprenaline $(0.1 \mathrm{nM}-10 \mu \mathrm{M})$. Although the inotropic response in diabetics seems to have decreased slightly compared to controls, this decrease was lower than expected (Fig. 4a). The contraction response in the EMPA group was very similar to the control group. On the other hand, treatment with EMPA did not ameliorate the decreased contractility (Fig. 4b). Corresponding $\mathrm{pEC}_{50}$ values in the four groups were also similar across groups $(7.26 \pm 0.29,7.23 \pm 0.19,7.22 \pm 0.19$ and $7.32 \pm 0.31)$.

\section{Discussion}

\section{Critique of methods}

Our laboratory has induced experimental diabetes in previous studies by STZ injection at doses between 32-45 mg/kg so far (32 mg/kg i.v., (Onay-Besikci et al., 2007); $35 \mathrm{mg} / \mathrm{kg}$ i.v., (Hafez et al., 2014); 35 $\mathrm{mg} / \mathrm{kg}$ i.v., (Gonulalan et al., 2012); $38 \mathrm{mg} / \mathrm{kg}$ i.p., (Arioglu-Inan et al., 2013); 40mg/kg i.v., (Ozakca et al., 2007); 40 mg/kg i.p., (Kayki-Mutlu et al., 2019); 45 mg/kg i.v., (Kayki-Mutlu et al., 2014)). Despite higher doses in many published studies (Arioglu Inan et al., 2018), we preferred to use low doses of STZ because we observed a greater mortality rate with higher doses. Besides, in all of our previous studies, we 
have confirmed the severity of diabetic status regarding metabolic parameters such as blood glucose level or body weight. Furthermore, $\beta$-AR mediated contractility of isolated papillary muscle was also markedly impaired at a STZ dose of $38 \mathrm{mg} / \mathrm{kg}$ (Arioglu-Inan et al., 2013). Supporting our results, it has been stated that $40 \mathrm{mg} / \mathrm{kg}$ dose of STZ induced a diabetic status with little mortality (Mostafavinia et al.,

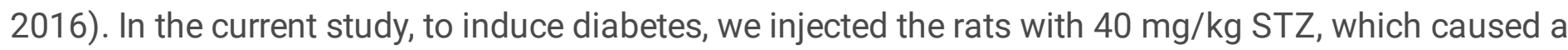
major increase in blood glucose; however, this was not associated with the severe cardiac impairment that is normally seen in the STZ diabetic rat model.

We used crushed tablets for the treatment with EMPA, and the reduced blood glucose levels confirm that this resulted in efficacious delivery of the treatment. While we cannot exclude that excipients have contributed to that, we consider this unlikely. In a previous study crushed dapagliflozin tablets had also effectively decreased blood glucose (Yesilyurt et al., 2019). As we discussed also in that study, using tablets may enhance the translational value of the study as it better mimicks the clinical condition.

Some studies have reported that the effects of EMPA differ depending on the selected dose (Oelze et al., 2014, Steven et al., 2017, Zhou and Wu, 2017). The current study aimed to investigate the effectiveness of low-dose of EMPA ( $10 \mathrm{mg} / \mathrm{kg}$ ) on cardiac function in an STZ-induced diabetes rat model to inform the design of a future study. This dose was consistently found to be effective on blood glucose, whereas only higher doses were effective on some echocardiographic parameters such as LAD (left atrial diameter), IVST (interventricular septum), LVPWT (left ventricular posterior wall) in another study (Shao et al., 2019). We had chosen the low dose as some previous studies have indicated that even the low dose of the drug is effective although both low and high doses of EMPA have been used in several studies in rats (Steven et al., 2017, Zhou and Wu, 2017, Shao et al., 2019). For instance, Zhou and Wu have reported that treatment with EMPA for 8 weeks reversed the deterioration of cardiac parameters in high-fat diet/low dose STZ-injected diabetic rats, even at the low dose of drug also used in that study. Nonetheless, blood glucose lowering activity and improvement in the cardiac function were more prominent in rats treated with high dose EMPA (Zhou and Wu, 2017). Moreover, presenting both diabetes and hypertension, CohenRosenthal diabetic hypertensive rats $(\mathrm{CRDH})$ had improved left ventricle mass and systolic dilatation after 11-week of low dose EMPA treatment (Younis et al., 2018). However, we did not observe a beneficial effect of low dose EMPA on cardiac function in STZ diabetic rats.

Another reason for the lack of a remarkable difference between the groups may be the sample size. When we designed the study, we had set seven rats each for control groups, nine and eleven rats for diabetic and EMPA treated diabetic rats, respectively. However, more rats died than expected and we started the experiments with fewer animals than planned. In addition, we were unable to obtain data for some of the rats in both in vivo and in vitro studies. Especially, the sample size for control group in the papillary muscle experiments was so small which may have affected the results.

\section{In vivo cardiac function}

The relationship between diabetes and cardiovascular disease is well known (Kannel and McGee, 1979). Changes in the left ventricular (LV) structure and function are the prominent features of the diabetic heart. 
Although impaired diastolic function is an earlier finding of the diabetic heart, systolic dysfunction may also accompany in the later stages (Bugger and Abel, 2014). Many studies have demonstrated that diastolic and systolic function is disrupted in the experimental diabetes (Connelly et al., 2007, Kim et al., 2010, Arioglu-Inan et al., 2013). Left ventricular catheterization is a robust method to determine diastolic and systolic function. Analysing parameters such as EDP/EDV, -dp/dt or Tau values by left ventricle catheterization gives an idea on in vivo diastolic function of the animal. In the present study, we found that both $-\mathrm{dp} / \mathrm{dt}$ and Tau value were impaired in the diabetic rats whereas no significant alteration was observed in EDP or EDV. Our finding is in line with the previous studies (Radovits et al., 2009, Arioglu-Inan et al., 2013). On the other hand, 8-week low dose EMPA treatment slightly increased and decreased $\mathrm{dp} / \mathrm{dt}$ and Tau, respectively. Nonetheless, it did not restore diastolic parameters significantly. Our results are not consistent with the ones of Hammoudi et al.; as they presented improved diastolic parameters such as Tau and EDPVR in leptin deficient ob/ob mice by EMPA treatment (Hammoudi et al., 2017). Similarly, Zhou and Wu have also found that both low dose (10 mg/kg/day) and high dose (30 $\mathrm{mg} / \mathrm{kg} /$ day) EMPA corrected rate of relaxation and left ventricular end diastolic pressure in high fat fed and STZ injected rats (2017). The dose of EMPA was same in all studies with similar treatment periods. Thus, one possible explanation for the discrepency between ours and the other two studies may be the diabetes model as they used a model mimicking type 2 diabetes and we used STZ diabetic rats resembling type 1 diabetes.

The parameters on systolic function such as $+\mathrm{dp} / \mathrm{dt}$ and ESP were reduced in the diabetic rats. The major indicator of the systolic function, EF was not altered in diabetic rats in the present study. However, in such cases as diastolic dysfunction, EF may be preserved despite impaired systolic parameters. Supporting our data, it has been indicated that diastolic function was deteriorated whereas EF was preserved in diabetic rats (Connelly et al., 2007). The effect of EMPA on systolic parameters were similar with the ones of diastolic function. It slightly increased ESP and $+d p / d t$ in the diabetic rats. Similar to our findings, EMPA did not affect systolic parameters in leptin deficient ob/ob mice (Hammoudi et al., 2017) and $\mathrm{db} / \mathrm{db}$ mice (Habibi et al., 2017). On the other hand, Zhou and Wu have showed that EMPA treatment at low and high doses improved LVSP and $+d p / d t$ in high fat fed and STZ injected rats (2017). The fact that EMPA treatment did not alter systolic parameters in three different diabetes model may implicate that the drug is not effective on the systolic function in the diabetic heart in the first place. However, conflicting results between these three studies and the one by Zhou and Wu (2017) remain to be clarified.

Interestingly, EMPA exerts cardiac beneficial effect not only in the chronic treatment but also after acute administration. Pabel et al. tested the acute effect of the drug on cardiac contractility in BKS.Cg-Dock7m +/+ Leprdb/J mice. EMPA significantly reduced excessive diastolic tension by almost $19.1 \%$, although it did not alter systolic force. Furthermore, intravenous injection of EMPA $(25 \mathrm{mg} / \mathrm{kg})$ resulted in shortened isovolumetric relaxation time (IVRT) and increased the peak early and late diastolic filling velocities (the E/A ratio) in Zucker diabetic fatty rats (Pabel et al., 2018). However, no alteration was observed in EF in these rats. Of note, the positive effects of EMPA is not limited to diabetes. Even though it did not affect systolic function, acute EMPA administration markedly reduced diastolic tension in nondiabetic mice. Besides, the diastolic tension was decreased in human trabeculae with heart failure in the presence of 
increasing concentrations of the drug (Pabel et al., 2018). Actually, the efficacy of EMPA in nondiabetic conditions has been also reported in other studies. EMPA treatment has been found to improve cardiac function in nondiabetic rats with MI (Yurista et al., 2019). Similarly, load independent parameters of cardiac contractility such as ESPVR and PRSW were ameliorated by EMPA in post MI rats (Connelly et al., 2020). Lee et al. have demonstrated that cardiac fibrosis was reduced after EMPA treatment in high fat fed spontaneous hypertensive rats (2019a). These data implicate a salutary effect independent of glucose excretion.

The beneficial effects of EMPA on cardiac function have been attributed to various mechanisms. One of them is the impact on $\mathrm{Ca}^{++}$regulation. Activity of SERCA2a and suppressing effect of phospholamban (PLN) on SERCA2a is essential for relaxation and thereby contraction in the healthy heart (Koss and Kranias, 1996). Diastolic dysfunction has been often correlated with reduced activity of SERCA2a and SERCA2a/PLN ratio. Actually, this ratio was found to be increased after EMPA treatment in leptin deficient ob/ob diabetic mice (Hammoudi et al., 2017). In this study, improved diastolic function in the treated group was attributed to this effect. On the contrary, SERCA2a or PLN phosphorylation was not altered after EMPA treatment in post MI rats despite an improved contractility (Connelly et al., 2020). Mustroph et al. have indicated that the cardiac effect of EMPA is associated with reduced CaMKII activity. 24-hour EMPA exposure decreased CaMKII activity both in wild type and failing murine cardiomyocytes. It also attenuated CaMKII dependent RyR2 phosphorylation both in murine and human failing ventricular cardiomyoctes. Thus, EMPA ameliorated cardiac contraction by decreasing SR $\mathrm{Ca}^{++}$leak (Mustroph et al., 2018). Another possible mechanism was suggested by Baartscheer et al. They have demonstrated that EMPA reduced cytoplasmic $\mathrm{Na}^{+}$and $\mathrm{Ca}^{++}$levels, and increased mitochondrial $\mathrm{Ca}^{++}$levels through inhibiting $\mathrm{Na}^{+} / \mathrm{H}^{+}$exchanger activity in cardiomyocytes (Baartscheer et al., 2017). Regarding their results, Mustroph et al. determined $\mathrm{Na}^{+}$and diastolic $\mathrm{Ca}^{++}$to explain reduced CaMKII activation due to EMPA exposure. In fact, cytosolic $\left[\mathrm{Na}^{+}\right]_{i}$ and diastolic $\left[\mathrm{Ca}^{++}\right]_{i}$ were decreased in the presence of the drug (2018).

There are many other hypotheses about the pleiotropic effects of EMPA. For instance, natriuretic or osmotic diuretic effect may have contributed to decreasing both cardiac preload and afterload (Lytvyn et al., 2017). Modulation on myocardial energy metabolism is another idea which has been related with EMPA (Ferrannini et al., 2016). However, more studies are needed to clarify the underlying mechanisms of cardiac effects of EMPA. Unfortunately, we were unable to investigate the role of the drug on the underlying mechanisms or signaling pathways in this current study.

\section{B-Adrenoceptor mediated responses}

The second aim of the present study was to determine the possible effect of low dose EMPA on $\beta$-AR mediated contraction. We did not observe any effect on isoprenaline induced contractile response in the EMPA treated group. Maximum response to isoprenaline was similar in diabetic and EMPA treated diabetic rats. On the other hand, it may be inaccurate to evaluate the efficacy of the drug in the current study as the contractility was not markedly deteriorated in the diabetic state as we discussed in the "critique of methods" section, this may have resulted from the lack of a severe diabetic status. We are 
aware that the reduced $\beta$-AR responsiveness is a well-known characteristic of the diabetic rat heart (Dincer et al., 1998, Jiang et al., 2015). Positive inotropic and chronotropic effects by $\beta$-AR agonist stimulation have been reported to be markedly attenuated in diabetic animal models (Ramanadham and Tenner, 1987, Dincer et al., 1998, Jiang et al., 2015).

We have also demonstrated that isoprenaline induced contraction of isolated papillary muscle was reduced in STZ diabetic rats (Arioglu-Inan et al., 2013). Furthermore, in that study, we have found that reduced contraction was accompanied by decreased expression of $\beta_{1}$-AR mRNA. Decreased expression of $\beta$-ARs due to diabetes has been reported in several studies (Dincer et al., 2001, Haley et al., 2015, Jiang et al., 2015, Okatan et al., 2015). Since we exclusively aimed to test the efficacy of low dose EMPA in the current study, we did not conduct further experiments on signaling pathway (mRNA, protein etc.) of $\beta$-AR mediated contractility. Therefore, we have no idea how receptors, second messengers or components in the $\mathrm{Ca}^{++}$homeostasis were affected by low dose EMPA treatment. Thus, we need to investigate the effect of EMPA on $\beta$-adrenergic responsiveness by using a higher dose of EMPA in a severe diabetic condition.

\section{Conclusions}

In the current study, we confirmed the glucose lowering effect of low dose EMPA in low-dose STZ diabetic rats. However, it did not alter in vivo cardiac function or $\beta$-AR-mediated contractility. Possible explanations might be; i) the lack of a severe diabetic status, ii) limited impairment of cardiac function by STZ, iii) small sample size for some of the groups and iv) the selected low dose of EMPA. Nonetheless, this current study achieved its aim as we indicated that the low dose of EMPA is not effective on the cardiac parameters we determined. Based on the results of this study, we decided to use a higher dose of STZ to induce a diabetic condition with more pronounced cardiac dysfunction and to use a higher dose of EMPA in our future study.

\section{Declarations}

\section{Funding}

This study was funded by grants from the Scientific and Technological Research Council of Turkey (TUBITAK SBAG-119S769). ZEY is a PhD student supported by TUBITAK (2211/A). GO is an undergraduate student supported by TUBITAK (119S769).

\section{Conflicts of interest}

The authors report no conflict of interest.

\section{Availability of data and material}

The raw data of the current study are available upon request.

\section{Authors' contributions}


EAI and ZEY designed the study. EAI, ZEY, IK and GO performed the experiments. BRE participated in the weekly follow-up of animals and the process of developing diabetes. EAI and ZEY made statistical analysis and drafted the manuscript. MM, EAI and ZEY revised the final draft of the manuscript. All authors have read the manuscript and approved the final version. The authors declare that all data were generated in-house and that no paper mill was used.

\section{Additional declarations for articles in life science journals that report the results of studies involving humans and/or animals}

Not applicable.

\section{Ethics approval}

All the animal handling procedures of the present study were approved by the Animal Welfare Commitee of Ankara University (2019-4-41).

\section{Consent to participate}

All authors have given consent to their contribution.

\section{Consent for publication}

All authors have agreed the consent to publish.

\section{References}

1. Arioglu-Inan E, Ozakca I, Kayki-Mutlu G, Sepici-Dincel A, Altan VM (2013) The role of insulin-thyroid hormone interaction on beta-adrenoceptor-mediated cardiac responses. Eur J Pharmacol 718: 533543. DOI 10.1016/j.ejphar.2013.06.021

2. Arioglu Inan E, Ellenbroek JH, Michel MC (2018) A systematic review of urinary bladder hypertrophy in experimental diabetes: Part I. Streptozotocin-induced rat models. Neurourol Urodyn 37: 1212-1219. DOI 10.1002/nau. 23490

3. Arow M, Waldman M, Yadin D, Nudelman V, Shainberg A, Abraham NG, Freimark D, Kornowski R, Aravot D, Hochhauser E, Arad M (2020) Sodium-glucose cotransporter 2 inhibitor Dapagliflozin attenuates diabetic cardiomyopathy. Cardiovasc Diabetol 19: 7. DOI 10.1186/s12933-019-0980-4

4. Baartscheer A, Schumacher CA, Wust RC, Fiolet JW, Stienen GJ, Coronel R, Zuurbier CJ (2017) Empagliflozin decreases myocardial cytoplasmic $\mathrm{Na}(+)$ through inhibition of the cardiac $\mathrm{Na}(+) / \mathrm{H}(+)$ exchanger in rats and rabbits. Diabetologia 60: 568-573. DOI 10.1007/s00125-016-4134-x

5. Bugger H, Abel ED (2014) Molecular mechanisms of diabetic cardiomyopathy. Diabetologia 57: 660671. DOI 10.1007/s00125-014-3171-6

6. Cho NH, Shaw JE, Karuranga S, Huang Y, da Rocha Fernandes JD, Ohlrogge AW, Malanda B (2018) IDF Diabetes Atlas: Global estimates of diabetes prevalence for 2017 and projections for 2045. 
Diabetes Res Clin Pract 138: 271-281. DOI 10.1016/j.diabres.2018.02.023

7. Connelly KA, Kelly DJ, Zhang Y, Prior DL, Martin J, Cox AJ, Thai K, Feneley MP, Tsoporis J, White KE, Krum H, Gilbert RE (2007) Functional, structural and molecular aspects of diastolic heart failure in the diabetic (mRen-2) 27 rat. Cardiovasc Res 76: 280-291. DOI 10.1016/j.cardiores.2007.06.022

8. Connelly KA, Zhang Y, Desjardins JF, Nghiem L, Visram A, Batchu SN, Yerra VG, Kabir G, Thai K, Advani A, Gilbert RE (2020) Load-independent effects of empagliflozin contribute to improved cardiac function in experimental heart failure with reduced ejection fraction. Cardiovasc Diabetol 19: 13. DOI 10.1186/s12933-020-0994-y

9. Cosentino F, Cannon CP, Cherney DZI, Masiukiewicz U, Pratley R, Dagogo-Jack S, Frederich R, Charbonnel B, Mancuso J, Shih WJ, Terra SG, Cater NB, Gantz I, McGuire DK, Investigators VC (2020) Efficacy of Ertugliflozin on Heart Failure-Related Events in Patients With Type 2 Diabetes Mellitus and Established Atherosclerotic Cardiovascular Disease: Results of the VERTIS CV Trial. Circulation 142: 2205-2215. DOI 10.1161/CIRCULATIONAHA.120.050255

10. Dincer UD, Bidasee KR, Guner S, Tay A, Ozcelikay AT, Altan VM (2001) The effect of diabetes on expression of beta1-, beta2-, and beta3-adrenoreceptors in rat hearts. Diabetes 50: 455-461. DOI 10.2337/diabetes.50.2.455

11. Dincer UD, Onay A, Ari N, Ozcelikay AT, Altan VM (1998) The effects of diabetes on beta-adrenoceptor mediated responsiveness of human and rat atria. Diabetes Res Clin Pract 40: 113-122. DOI 10.1016/s0168-8227(98)00034-5

12. Duckworth W, Abraira C, Moritz T, Reda D, Emanuele N, Reaven PD, Zieve FJ, Marks J, Davis SN, Hayward R, Warren SR, Goldman S, McCarren M, Vitek ME, Henderson WG, Huang GD, Investigators V (2009) Glucose control and vascular complications in veterans with type 2 diabetes. N Engl J Med 360: 129-139. DOI 10.1056/NEJMoa0808431

13. Erdogan BR, Vollert J, Michel MC (2020) Choice of y-axis can mislead readers. Naunyn Schmiedebergs Arch Pharmacol 393: 1769-1772. DOI 10.1007/s00210-020-01926-x

14. Ferrannini E, Mark M, Mayoux E (2016) CV Protection in the EMPA-REG OUTCOME Trial: A "Thrifty Substrate" Hypothesis. Diabetes Care 39: 1108-1114. DOI 10.2337/dc16-0330

15. Garg SK, Henry RR, Banks P, Buse JB, Davies MJ, Fulcher GR, Pozzilli P, Gesty-Palmer D, Lapuerta P, Simo R, Danne T, McGuire DK, Kushner JA, Peters A, Strumph P (2017) Effects of Sotagliflozin Added to Insulin in Patients with Type 1 Diabetes. N Engl J Med 377: 2337-2348. DOI

10.1056/NEJMoa1708337

16. Gauthier C, Tavernier G, Charpentier F, Langin D, Le Marec H (1996) Functional beta3-adrenoceptor in the human heart. J Clin Invest 98: 556-562. DOI 10.1172/JCl118823

17. Gerstein HC, Miller ME, Byington RP, Goff DC, Jr., Bigger JT, Buse JB, Cushman WC, Genuth S, IsmailBeigi F, Grimm RH, Jr., Probstfield JL, Simons-Morton DG, Friedewald WT (2008) Effects of intensive glucose lowering in type 2 diabetes. N Engl J Med 358: 2545-2559. DOI 10.1056/NEJMoa0802743

18. Gonulalan U, Kosan M, Hafez G, Arioglu E, Akdemir O, Ozturk B, Gur S, Cetinkaya M (2012) The effect of diabetes mellitus on alpha1-adrenergic receptor subtypes in the bladder of rats. Urology 80: 951 
e959-916. DOI 10.1016/j.urology.2012.06.019

19. Group AC, Patel A, MacMahon S, Chalmers J, Neal B, Billot L, Woodward M, Marre M, Cooper M, Glasziou P, Grobbee D, Hamet P, Harrap S, Heller S, Liu L, Mancia G, Mogensen CE, Pan C, Poulter N, Rodgers A, Williams B, Bompoint S, de Galan BE, Joshi R, Travert F (2008) Intensive blood glucose control and vascular outcomes in patients with type 2 diabetes. N Engl J Med 358: 2560-2572. DOI 10.1056/NEJMoa0802987

20. Habibi J, Aroor AR, Sowers JR, Jia G, Hayden MR, Garro M, Barron B, Mayoux E, Rector RS, WhaleyConnell A, DeMarco VG (2017) Sodium glucose transporter 2 (SGLT2) inhibition with empagliflozin improves cardiac diastolic function in a female rodent model of diabetes. Cardiovasc Diabetol 16: 9. DOI 10.1186/s12933-016-0489-z

21. Hafez G, Gonulalan U, Kosan M, Arioglu E, Ozturk B, Cetinkaya M, Gur S (2014) Acetylsalicylic acid protects erectile function in diabetic rats. Andrologia 46: 997-1003. DOI 10.1111/and.12187

22. Haley JM, Thackeray JT, Kolajova M, Thorn SL, DaSilva JN (2015) Insulin therapy normalizes reduced myocardial beta-adrenoceptors at both the onset and after sustained hyperglycemia in diabetic rats. Life Sci 132: 101-107. DOI 10.1016/j.Ifs.2015.03.024

23. Hammoudi N, Jeong D, Singh R, Farhat A, Komajda M, Mayoux E, Hajjar R, Lebeche D (2017) Empagliflozin Improves Left Ventricular Diastolic Dysfunction in a Genetic Model of Type 2 Diabetes. Cardiovasc Drugs Ther 31: 233-246. DOI 10.1007/s10557-017-6734-1

24. Jiang C, Carillion A, Na N, De Jong A, Feldman S, Lacorte JM, Bonnefont-Rousselot D, Riou B, Amour $J$ (2015) Modification of the beta-Adrenoceptor Stimulation Pathway in Zucker Obese and Obese Diabetic Rat Myocardium. Crit Care Med 43: e241-249. DOI 10.1097/CCM.0000000000000999

25. Kannel WB, McGee DL (1979) Diabetes and cardiovascular disease. The Framingham study. JAMA 241: 2035-2038. DOI 10.1001/jama.241.19.2035

26. Kayki-Mutlu G, Arioglu-Inan E, Ozakca I, Ozcelikay AT, Altan VM (2014) beta3-Adrenoceptor-mediated responses in diabetic rat heart. Gen Physiol Biophys 33: 99-109. DOI 10.4149/gpb_2013065

27. Kayki-Mutlu G, Karaomerlioglu I, Arioglu-Inan E (2019) The effect of nitric oxide synthase on beta 3 adrenoceptor mediated relaxation in STZ diabetic rat heart. . Ankara Üniversitesi Eczacılık Fakültesi Dergisi 43(1): 64-71.

28. Kim DH, Kim YJ, Kim HK, Chang SA, Kim MS, Sohn DW, Oh BH, Park YB (2010) Usefulness of mitral annulus velocity for the early detection of left ventricular dysfunction in a rat model of diabetic cardiomyopathy. J Cardiovasc Ultrasound 18: 6-11. DOI 10.4250/jcu.2010.18.1.6

29. Kosiborod M, Cavender MA, Fu AZ, Wilding JP, Khunti K, Holl RW, Norhammar A, Birkeland KI, Jorgensen ME, Thuresson M, Arya N, Bodegard J, Hammar N, Fenici P, Investigators C-R, Study G (2017) Lower Risk of Heart Failure and Death in Patients Initiated on Sodium-Glucose Cotransporter2 Inhibitors Versus Other Glucose-Lowering Drugs: The CVD-REAL Study (Comparative Effectiveness of Cardiovascular Outcomes in New Users of Sodium-Glucose Cotransporter-2 Inhibitors). Circulation 136: 249-259. DOI 10.1161/CIRCULATIONAHA.117.029190 
30. Koss KL, Kranias EG (1996) Phospholamban: a prominent regulator of myocardial contractility. Circ Res 79: 1059-1063. DOI 10.1161/01.res.79.6.1059

31. Lee HC, Shiou YL, Jhuo SJ, Chang CY, Liu PL, Jhuang WJ, Dai ZK, Chen WY, Chen YF, Lee AS (2019a) The sodium-glucose co-transporter 2 inhibitor empagliflozin attenuates cardiac fibrosis and improves ventricular hemodynamics in hypertensive heart failure rats. Cardiovasc Diabetol 18: 45. DOI 10.1186/s12933-019-0849-6

32. Lee TI, Chen YC, Lin YK, Chung CC, Lu YY, Kao YH, Chen YJ (2019b) Empagliflozin Attenuates Myocardial Sodium and Calcium Dysregulation and Reverses Cardiac Remodeling in StreptozotocinInduced Diabetic Rats. Int J Mol Sci 20DOI 10.3390/ijms20071680

33. Lim VG, Bell RM, Arjun S, Kolatsi-Joannou M, Long DA, Yellon DM (2019) SGLT2 Inhibitor, Canagliflozin, Attenuates Myocardial Infarction in the Diabetic and Nondiabetic Heart. JACC Basic Transl Sci 4: 15-26. DOI 10.1016/j.jacbts.2018.10.002

34. Lytvyn Y, Bjornstad P, Udell JA, Lovshin JA, Cherney DZI (2017) Sodium Glucose Cotransporter-2 Inhibition in Heart Failure: Potential Mechanisms, Clinical Applications, and Summary of Clinical Trials. Circulation 136: 1643-1658. DOI 10.1161/CIRCULATIONAHA.117.030012

35. McMurray JJV, DeMets DL, Inzucchi SE, Kober L, Kosiborod MN, Langkilde AM, Martinez FA, Bengtsson O, Ponikowski P, Sabatine MS, Sjostrand M, Solomon SD, Committees D-H, Investigators (2019) A trial to evaluate the effect of the sodium-glucose co-transporter 2 inhibitor dapagliflozin on morbidity and mortality in patients with heart failure and reduced left ventricular ejection fraction (DAPA-HF). Eur J Heart Fail 21: 665-675. DOI 10.1002/ejhf.1432

36. Michel MC, Mayoux E, Vallon V (2015) A comprehensive review of the pharmacodynamics of the SGLT2 inhibitor empagliflozin in animals and humans. Naunyn Schmiedebergs Arch Pharmacol 388: 801-816. DOI 10.1007/s00210-015-1134-1

37. Michel MC, Murphy TJ, Motulsky HJ (2020) New Author Guidelines for Displaying Data and Reporting Data Analysis and Statistical Methods in Experimental Biology. Mol Pharmacol 97: 49-60. DOI 10.1124/mol.119.118927

38. Mostafavinia A, Amini A, Ghorishi SK, Pouriran R, Bayat M (2016) The effects of dosage and the routes of administrations of streptozotocin and alloxan on induction rate of type 1 diabetes mellitus and mortality rate in rats. Lab Anim Res 32: 160-165. DOI 10.5625/lar.2016.32.3.160

39. Mustroph J, Wagemann O, Lucht CM, Trum M, Hammer KP, Sag CM, Lebek S, Tarnowski D, Reinders J, Perbellini F, Terracciano C, Schmid C, Schopka S, Hilker M, Zausig Y, Pabel S, Sossalla ST, Schweda F, Maier LS, Wagner S (2018) Empagliflozin reduces Ca/calmodulin-dependent kinase II activity in isolated ventricular cardiomyocytes. ESC Heart Fail 5: 642-648. DOI 10.1002/ehf2.12336

40. Neal B, Perkovic V, Mahaffey KW, de Zeeuw D, Fulcher G, Erondu N, Shaw W, Law G, Desai M, Matthews DR, Group CPC (2017) Canagliflozin and Cardiovascular and Renal Events in Type 2 Diabetes. N Engl J Med 377: 644-657. DOI 10.1056/NEJMoa1611925

41. Oelze $M$, Kroller-Schon $S$, Welschof $P$, Jansen $T$, Hausding M, Mikhed $Y$, Stamm P, Mader M, Zinssius E, Agdauletova S, Gottschlich A, Steven S, Schulz E, Bottari SP, Mayoux E, Munzel T, Daiber A (2014) 
The sodium-glucose co-transporter 2 inhibitor empagliflozin improves diabetes-induced vascular dysfunction in the streptozotocin diabetes rat model by interfering with oxidative stress and glucotoxicity. PLoS One 9: e112394. DOI 10.1371/journal.pone.0112394

42. Okatan EN, Tuncay E, Hafez G, Turan B (2015) Profiling of cardiac beta-adrenoceptor subtypes in the cardiac left ventricle of rats with metabolic syndrome: Comparison with streptozotocin-induced diabetic rats. Can J Physiol Pharmacol 93: 517-525. DOI 10.1139/cjpp-2014-0507

43. Onay-Besikci A, Guner S, Arioglu E, Ozakca I, Ozcelikay AT, Altan VM (2007) The effects of chronic trimetazidine treatment on mechanical function and fatty acid oxidation in diabetic rat hearts. Can $\mathrm{J}$ Physiol Pharmacol 85: 527-535. DOI 10.1139/y07-036

44. Ozakca I, Arioglu E, Guner S, Altan VM, Ozcelikay AT (2007) Role of beta-3-adrenoceptor in catecholamine-induced relaxations in gastric fundus from control and diabetic rats. Pharmacology 80: 227-238. DOI 10.1159/000104876

45. Pabel S, Wagner S, Bollenberg H, Bengel P, Kovacs A, Schach C, Tirilomis P, Mustroph J, Renner A, Gummert J, Fischer T, Van Linthout S, Tschope C, Streckfuss-Bomeke K, Hasenfuss G, Maier LS, Hamdani N, Sossalla S (2018) Empagliflozin directly improves diastolic function in human heart failure. Eur J Heart Fail 20: 1690-1700. DOI 10.1002/ejhf.1328

46. Pennig J, Scherrer P, Gissler MC, Anto-Michel N, Hoppe N, Funer L, Hardtner C, Stachon P, Wolf D, Hilgendorf I, Mullick A, Bode C, Zirlik A, Goldberg IJ, Willecke F (2019) Glucose lowering by SGLT2inhibitor empagliflozin accelerates atherosclerosis regression in hyperglycemic STZ-diabetic mice. Sci Rep 9: 17937. DOI 10.1038/s41598-019-54224-9

47. Radovits T, Korkmaz S, Loganathan S, Barnucz E, Bomicke T, Arif R, Karck M, Szabo G (2009) Comparative investigation of the left ventricular pressure-volume relationship in rat models of type 1 and type 2 diabetes mellitus. Am J Physiol Heart Circ Physiol 297: H125-133. DOI 10.1152/ajpheart.00165.2009

48. Ramanadham S, Tenner TE, Jr. (1987) Alterations in the myocardial beta-adrenoceptor system of streptozotocin-diabetic rats. Eur J Pharmacol 136: 377-389. DOI 10.1016/0014-2999(87)90311-6

49. Rosenstock J, Marquard J, Laffel LM, Neubacher D, Kaspers S, Cherney DZ, Zinman B, Skyler JS, George J, Soleymanlou N, Perkins BA (2018) Empagliflozin as Adjunctive to Insulin Therapy in Type 1 Diabetes: The EASE Trials. Diabetes Care 41: 2560-2569. DOI 10.2337/dc18-1749

50. Shao Q, Meng L, Lee S, Tse G, Gong M, Zhang Z, Zhao J, Zhao Y, Li G, Liu T (2019) Empagliflozin, a sodium glucose co-transporter-2 inhibitor, alleviates atrial remodeling and improves mitochondrial function in high-fat diet/streptozotocin-induced diabetic rats. Cardiovasc Diabetol 18: 165. DOI 10.1186/s12933-019-0964-4

51. Steven S, Oelze M, Hanf A, Kroller-Schon S, Kashani F, Roohani S, Welschof P, Kopp M, GodtelArmbrust U, Xia N, Li H, Schulz E, Lackner KJ, Wojnowski L, Bottari SP, Wenzel P, Mayoux E, Munzel T, Daiber A (2017) The SGLT2 inhibitor empagliflozin improves the primary diabetic complications in ZDF rats. Redox Biol 13: 370-385. DOI 10.1016/j.redox.2017.06.009 
52. Wentworth JM, Fourlanos S, Colman PG, Harrison LC (2020) A pilot study of the feasibility of empagliflozin in recent-onset type 1 diabetes. Metabolism Open: 100021.

53. Wiviott SD, Raz I, Bonaca MP, Mosenzon O, Kato ET, Cahn A, Silverman MG, Zelniker TA, Kuder JF, Murphy SA, Bhatt DL, Leiter LA, McGuire DK, Wilding JPH, Ruff CT, Gause-Nilsson IAM, Fredriksson M, Johansson PA, Langkilde AM, Sabatine MS, Investigators D-T (2019) Dapagliflozin and Cardiovascular Outcomes in Type 2 Diabetes. N Engl J Med 380: 347-357. DOI 10.1056/NEJMoa1812389

54. Yesilyurt ZE, Erdogan BR, Karaomerlioglu I, Muderrisoglu AE, Michel MC, Arioglu-Inan E (2019) Urinary Bladder Weight and Function in a Rat Model of Mild Hyperglycemia and Its Treatment With Dapagliflozin. Front Pharmacol 10: 911. DOI 10.3389/fphar.2019.00911

55. Younis F, Leor J, Abassi Z, Landa N, Rath L, Hollander K, Naftali-Shani N, Rosenthal T (2018) Beneficial Effect of the SGLT2 Inhibitor Empagliflozin on Glucose Homeostasis and Cardiovascular Parameters in the Cohen Rosenthal Diabetic Hypertensive (CRDH) Rat. J Cardiovasc Pharmacol Ther 23: 358-371. DOI 10.1177/1074248418763808

56. Yurista SR, Sillje HHW, Oberdorf-Maass SU, Schouten EM, Pavez Giani MG, Hillebrands JL, van Goor H, van Veldhuisen DJ, de Boer RA, Westenbrink BD (2019) Sodium-glucose co-transporter 2 inhibition with empagliflozin improves cardiac function in non-diabetic rats with left ventricular dysfunction after myocardial infarction. Eur J Heart Fail 21: 862-873. DOI 10.1002/ejhf.1473

57. Zhou Y, Wu W (2017) The Sodium-Glucose Co-Transporter 2 Inhibitor, Empagliflozin, Protects against Diabetic Cardiomyopathy by Inhibition of the Endoplasmic Reticulum Stress Pathway. Cell Physiol Biochem 41: 2503-2512. DOI 10.1159/000475942

58. Zinman B, Wanner C, Lachin JM, Fitchett D, Bluhmki E, Hantel S, Mattheus M, Devins T, Johansen OE, Woerle HJ, Broedl UC, Inzucchi SE, Investigators E-RO (2015) Empagliflozin, Cardiovascular Outcomes, and Mortality in Type 2 Diabetes. N Engl J Med 373: 2117-2128. DOI 10.1056/NEJMoa1504720

\section{Tables}

Table 1 In vivo basal hemodynamic parameters of rats. Values are presented as means \pm SD. SBP: Systolic blood pressure; DBP: diastolic blood pressure; MAP: mean arterial pressure HR: heart rate; CO: Cardiac output; SW: Stroke work; ESV: End systolic volume; EDV: End diastolic volume; SV: Stroke volume; EDVI: End diastolic volume index; ESVI: End systolic volume index; $\mathrm{Cl}$ : cardiac index; SVI: stroke volume index; C: Control; CE: EMPA-treated control; D: Diabetic; DE: EMPA-treated diabetic. Raw data are shown in Online Supplement 6. 


\begin{tabular}{|c|c|c|c|c|}
\hline & $C(n=7)$ & CE $(n=5)$ & $D(n=6)$ & DE $(n=8)$ \\
\hline SBP (mmHg) & $133.2 \pm 31.6$ & $123.4 \pm 10.5$ & $114.1 \pm 15.7$ & $116.0 \pm 12.9$ \\
\hline DBP (mmHg) & $94.8 \pm 25.1$ & $95.5 \pm 16.1$ & $85.2 \pm 6.9$ & $89.9 \pm 9.9$ \\
\hline MAP (mmHg) & $120.4 \pm 29.4$ & $114.1 \pm 12.0$ & $104.5 \pm 12.7$ & $107.3 \pm 11.5$ \\
\hline HR (beat/min) & $284.5 \pm 24.7$ & $281.8 \pm 10.7$ & $249.8 \pm 22.2$ & $242.0 \pm 19.2$ \\
\hline $\mathrm{CO}(\mathrm{ml} / \mathrm{min})$ & $55.4 \pm 11.6$ & $58.4 \pm 9.1$ & $39.0 \pm 4.9$ & $48.9 \pm 8.3$ \\
\hline $\mathrm{SW}(\mathrm{mmHg} / \mu \mathrm{l})$ & $21.7 \pm 3.6$ & $19.4 \pm 2.5$ & $15.7 \pm 3.3$ & $19.1 \pm 3.7$ \\
\hline EDV ( $(\mu)$ & $387.7 \pm 27.8$ & $374.2 \pm 50.4$ & $357.1 \pm 69.3$ & $390.8 \pm 52.7$ \\
\hline ESV $(\mu l)$ & $192.9 \pm 24.2$ & $166.7 \pm 26.1$ & $198.5 \pm 44.6$ & $187.9 \pm 29.3$ \\
\hline SV $(\mu l)$ & $194.8 \pm 37.6$ & $207.4 \pm 29.4$ & $158.6 \pm 30.4$ & $202.8 \pm 34.0$ \\
\hline $\operatorname{EDVI}\left(\mu \mathrm{l} / \mathrm{g} .10^{3}\right)$ & $0.91 \pm 0.09$ & $0.90 \pm 0.15$ & $1.03 \pm 0.20$ & $1.14 \pm 0.19$ \\
\hline $\operatorname{ESVI}\left(\mu \mathrm{l} / \mathrm{g} \cdot 10^{3}\right)$ & $0.45 \pm 0.08$ & $0.40 \pm 0.08$ & $0.57 \pm 0.12$ & $0.55 \pm 0.10$ \\
\hline $\mathrm{Cl}\left(\mathrm{ml} / \mathrm{min} \cdot \mathrm{g} \cdot 10^{3}\right)$ & $129.2 \pm 26.6$ & $140.7 \pm 23.2$ & $112.9 \pm 15.4$ & $142.5 \pm 26.0$ \\
\hline
\end{tabular}


Table 2 Preload independent in vivo cardiac parameters of rats. Values are presented as the mean \pm SD. ESPVR: End-systolic pressure-polume relationship; EDPVR: End-diastolic pressure-volume relationship; PRSW: Preload recruitable stroke work. Raw data are shown in Online Supplement 6.

\begin{tabular}{|lllll|}
\hline & & & & \\
& & & & \\
& & & & \\
ESPVR & $0.29 \pm 0.08$ & $0.33 \pm 0.15$ & $0.28 \pm 0.06$ & $0.32 \pm 0.10$ \\
EDPVR & $0.005 \pm 0.004$ & $0.006 \pm 0.003$ & $0.008 \pm 0.005$ & $0.008 \pm 0.006$ \\
& & & & \\
PRSW & $53.25 \pm 8.14$ & $57.68 \pm 10.67$ & $56.31 \pm 10.53$ & $52.87 \pm 6.26$ \\
\hline
\end{tabular}

Figures 

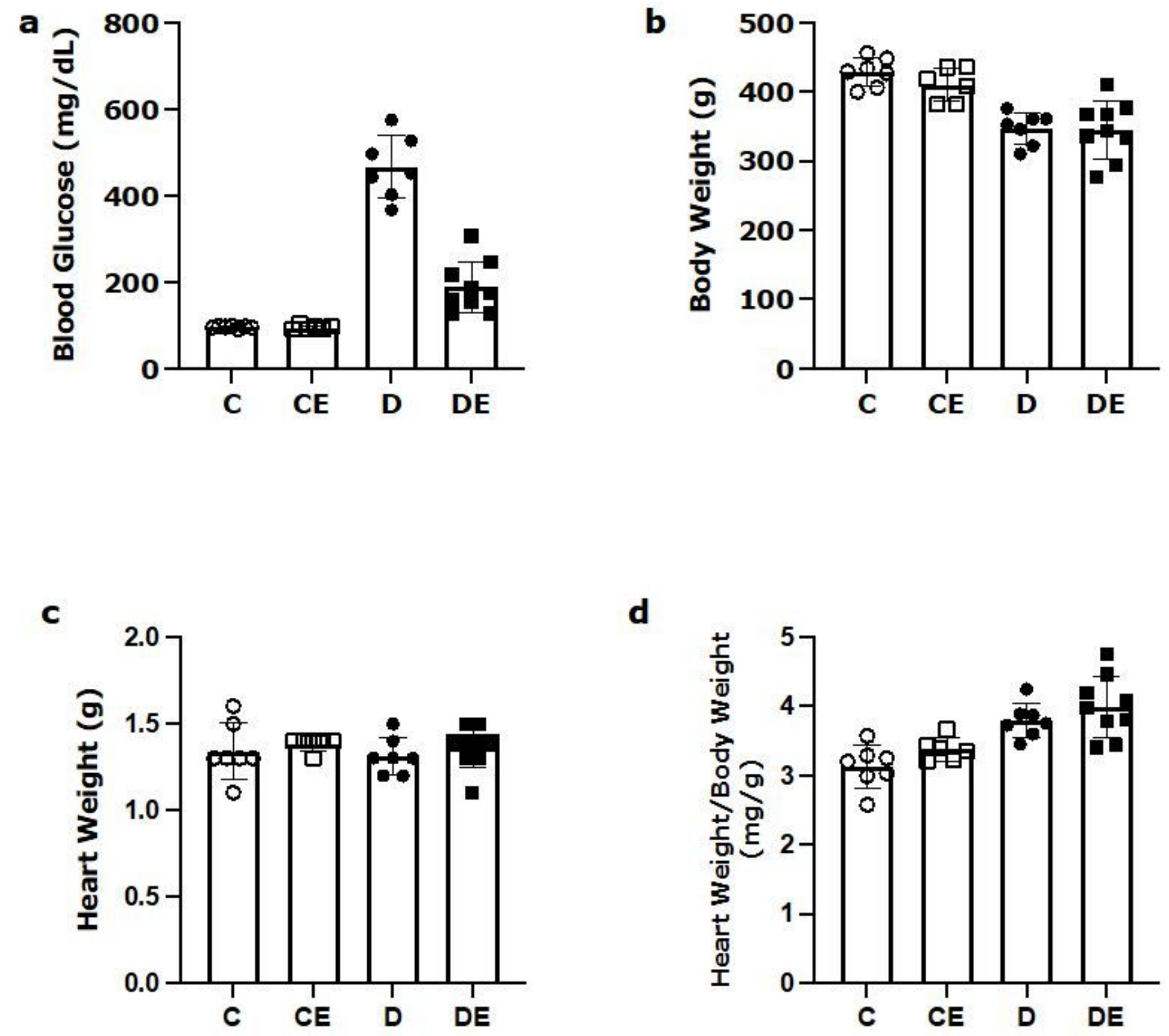

Figure 1

General characteristics of the rats. a Blood glucose (mg/dl) b Body weight $(\mathrm{g})$ c Heart weight $(\mathrm{g}) \mathrm{d}$ Ratio of heart weight to body weight. C: Control $(n=7), C E$ : EMPA-treated control $(n=6)$, D: Diabetic $(n=7), D E$ : EMPA-treated diabetic $(n=9)$. Raw data are shown in Online Supplement 1. 

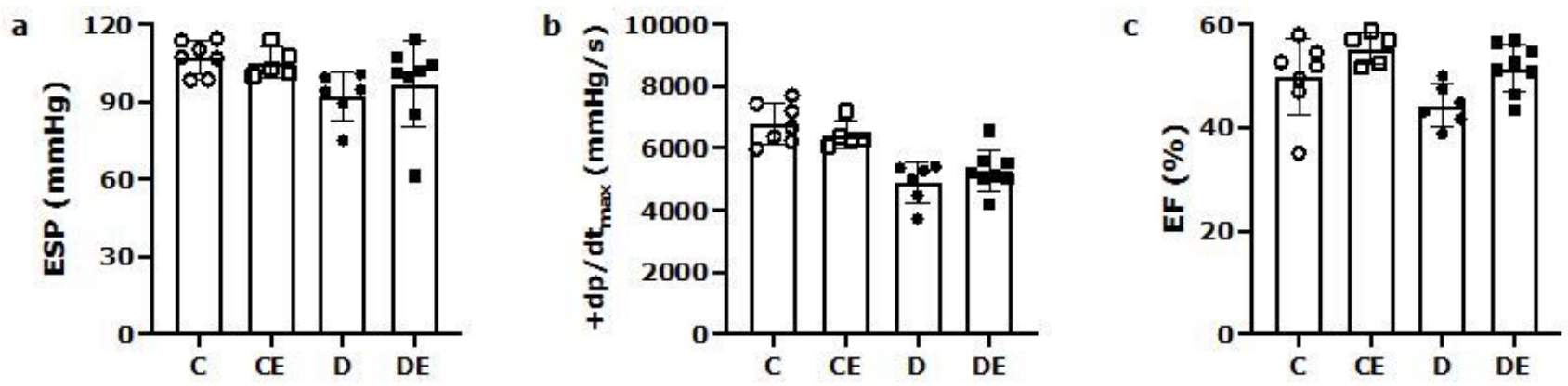

Figure 2

In vivo basal systolic parameters. a End systolic pressure (ESP) b Rate of contraction (+dp/dt) c Ejection fraction (EF). C: Control $(n=7), C E$ : EMPA-treated control $(n=5), D$ : Diabetic $(n=6)$, DE: EMPA-treated diabetic $(n=8)$. Raw data are shown in Online Supplement 2.

a

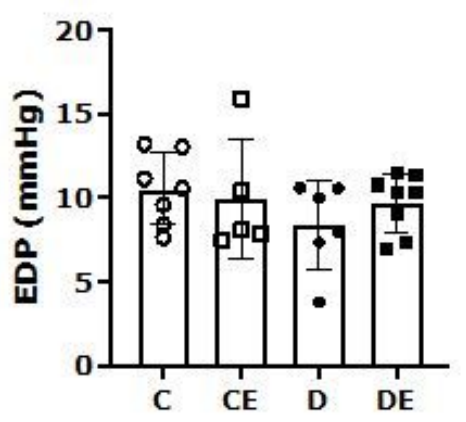

b

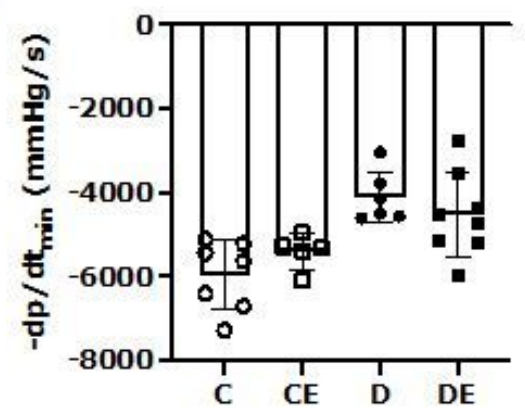

C

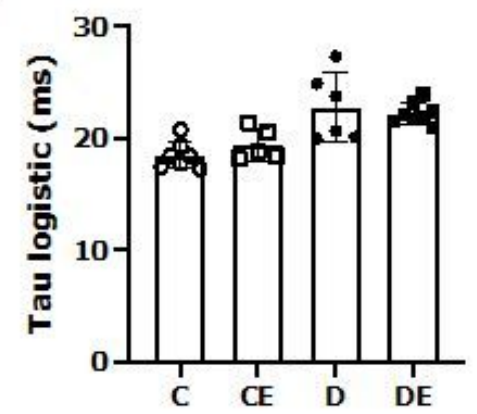

Figure 3

In vivo basal diastolic parameters. a End diastolic pressure (EDP) b Rate of relaxation (-dp/dt) c Isovolumic relaxation time constant (Tau). C: Control $(n=7)$, CE: EMPA-treated control $(n=5), D$ : Diabetic $(n=6)$, DE: EMPA-treated diabetic $(n=8)$. Raw data are shown in Online Supplement 3. 
a

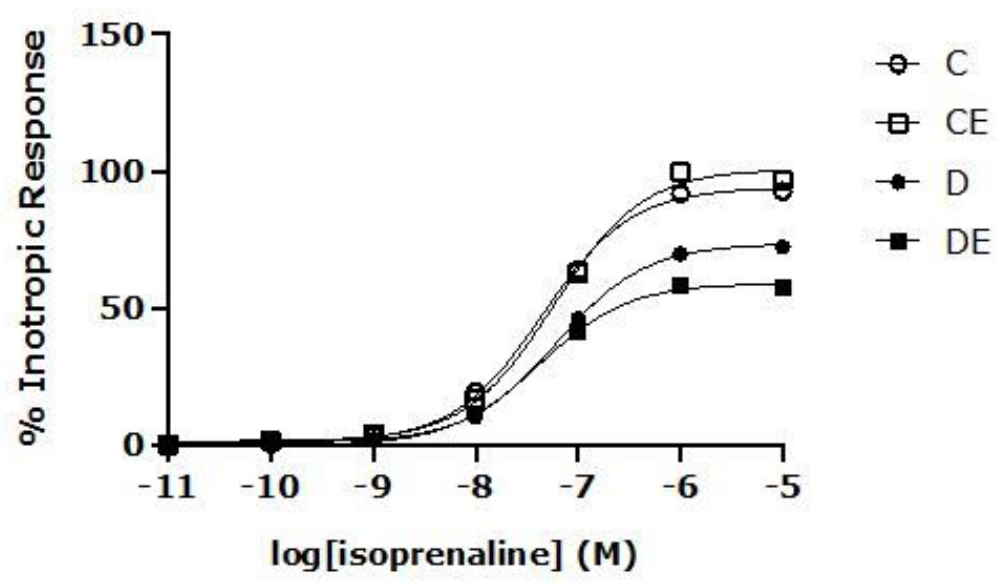

b $\quad E_{\max }$ isoprenaline

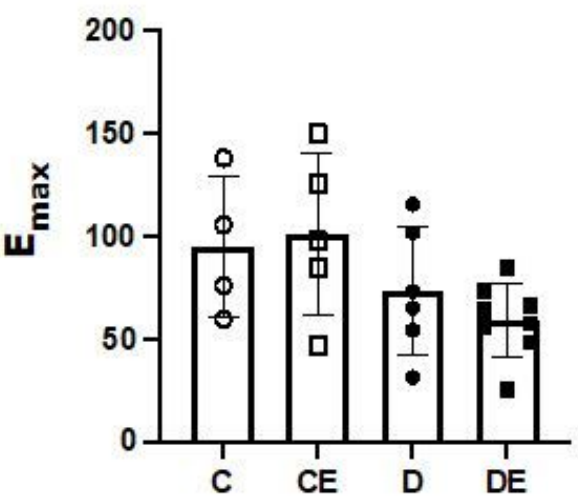

Figure 4

Contraction response. a Concentration-response curve of isoprenaline. b Maximal response (Emax) values for isoprenaline-induced contraction. C: Control $(n=4), C E$ : EMPA-treated control $(n=5), D$ : Diabetic $(n=6)$, DE: EMPA-treated diabetic $(n=8)$. Raw data are shown in Online Supplement 4.

\section{Supplementary Files}

This is a list of supplementary files associated with this preprint. Click to download.

- OnlineSuppl1.pzfx

- OnlineSuppl2.pzfx

- OnlineSuppl3.pzfx

- OnlineSuppl4.pzfx

- OnlineSuppl5.pzfx

- OnlineSuppl6.pzfx 